\title{
Native entomopathogenic Metarhizium spp. from Burkina Faso and their virulence against the malaria vector Anopheles coluzzii and non-target insects
}

\author{
Etienne Bilgo ${ }^{1,3^{*}}$, Brian Lovett ${ }^{2}$, Raymond J. St. Leger ${ }^{2}$, Antoine Sanon ${ }^{3}$, Roch K. Dabiré ${ }^{1}$ and Abdoulaye Diabaté ${ }^{1}$
}

\begin{abstract}
Background: Genetically enhanced Metarhizium pingshaense are being developed for malaria vector control in Burkina Faso. However, not much is known about the local prevalence and pathogenicity of this fungus, so we prospected mosquitoes and plant roots (a common habitat for Metarhizium spp.) for entomopathogenic fungi.

Results: Our investigations showed that Metarhizium spp. represented between 29-74\% of fungi isolated from plant root rhizospheres in diverse collection sites. At low spore dosages $\left(1 \times 10^{6}\right.$ conidia/ml), two mosquito-derived $M$. pingshaense isolates (Met_S26 and Met_S10) showed greater virulence against Anopheles coluzzii (LT 80 of $\sim 7$ days) than isolates tested in previous studies ( $L T_{80}$ of $\sim 10$ days). In addition, the local isolates did not cause disease in non-target insects (honeybees and cockroaches).

Conclusions: Our work provides promising findings for isolating local Metarhizium strains for application in mosquito biological control and for future transgenic biocontrol strategies in Burkina Faso.
\end{abstract}

Keywords: Metarhizium, Entomopathogenic fungi, Mosquitoes, Vector control, Honeybees, Cockroaches, Malaria, Burkina Faso

\section{Background}

Unlike mosquitocidal bacteria and viruses, ascomycete fungi can infect and kill insects without being ingested. As with chemical insecticides, tarsal contact alone is sufficient to kill mosquitoes [1]. Despite intensive efforts to develop entomopathogenic fungi as biocontrol agents against malaria vectors, the strains under investigation have not met expectations due to their poorer efficacy relative to cheaper chemical insecticides [2]. The United States Department of Agriculture (USDA) ARSEF collection (the world's largest collection of entomopathogenic fungi) has more than 12,000 isolates of insect pathogenic fungi. Of these, only 156 are from sub-Saharan Africa (South Africa and Benin are the source of 40 and 36

\footnotetext{
*Correspondence: bilgo02@yahoo.fr

${ }^{1}$ Institut de Recherche en Sciences de la Santé/Centre Muraz, Bobo-Dioulasso, Burkina Faso

${ }^{3}$ Laboratoire d'Entomologie Fondamentale et Appliqué/UFR-SVT/Université

Ouaga 1, Pr. Joseph KI-Zerbo, Ouagadougou, Burkina Faso

Full list of author information is available at the end of the article
}

isolates, respectively), with none from Burkina Faso. The mosquitocidal activity of Metarhizium has been enhanced by engineering them to express insect-selective neurotoxins [3-5], and a transgenic strain of Metarhizium pingshaense is being evaluated in semi-field trials in Burkina Faso [5]. We speculate that future development of transgenic fungi worldwide will preferentially use local isolates as these may be better adapted to kill local mosquitoes and survive harsh local conditions (i.e. rainy season heat, sunlight and humidity) than exotic strains. However, the distribution and properties of indigenous Burkinabe Metarhizium spp. have not been characterized. The first objective of this study was to prospect for the presence and distribution of local Metarhizium strains. As well as prospecting mosquitoes, we also sampled rhizosphere soils (i.e. the soil in the vicinity of plant roots that is influenced by root secretions), as some Metarhizium spp. are abundant in the rhizosphere and may function as symbionts promoting 
plant growth. The plant-beneficial effects of Metarhizium species correlate with their association with roots and are mediated via plant hormones [6]. The second objective was to evaluate the pathogenicity of local Metarhizium isolates against wild-caught, insecticideresistant Anopheles coluzzii. Finally, we also assessed the pathogenicity of the local isolates against American cockroaches and honeybees as representative non-target or beneficial species.

\section{Methods}

\section{Fungal collection, isolation and morphological identification}

Collections were carried out on a monthly basis during the 2015 rainy season (from July to September) from plant roots and wild-caught mosquitoes. Our three collection sites were the Kou Valley $\left(11^{\circ} 23^{\prime} \mathrm{N}, 4^{\circ} 24^{\prime} \mathrm{W}\right)$, a rice crop area; Bana $\left(11^{\circ} 9^{\prime} 41^{\prime \prime} \mathrm{N}, 4^{\circ} 10^{\prime} 30^{\prime \prime} \mathrm{W}\right)$, a savanna and forested area; and Soumousso $\left(11^{\circ} 04^{\prime} \mathrm{N}, 4^{\circ} 03^{\prime} \mathrm{W}\right)$, a savanna and corn crop area (Fig. 1). One hundred and fifty-five plants were sampled from these three different agro-ecological sites. We followed the protocol described in [7] to collect rhizosphere soil and isolate fungi. The fungal selective medium contained $42 \mathrm{~g}$ potato-dextrose agar, $0.5 \mathrm{~g}$ chloramphenicol and $0.6 \mathrm{~g}$ cetyl trimethylammonium bromide per liter.

Overall, 300 mosquitoes were collected from 3 types of resting sites (inhabited houses, abandoned houses and outdoor piles of wood). Mosquitoes were brought to the IRSS/Centre Muraz insectary, where they were fed on $6 \%$ sterile glucose ad libitum. Approximately $22 \%$ of collected mosquitoes (67 mosquitoes) died within 2 weeks and were plated on selective medium for fungal isolations.

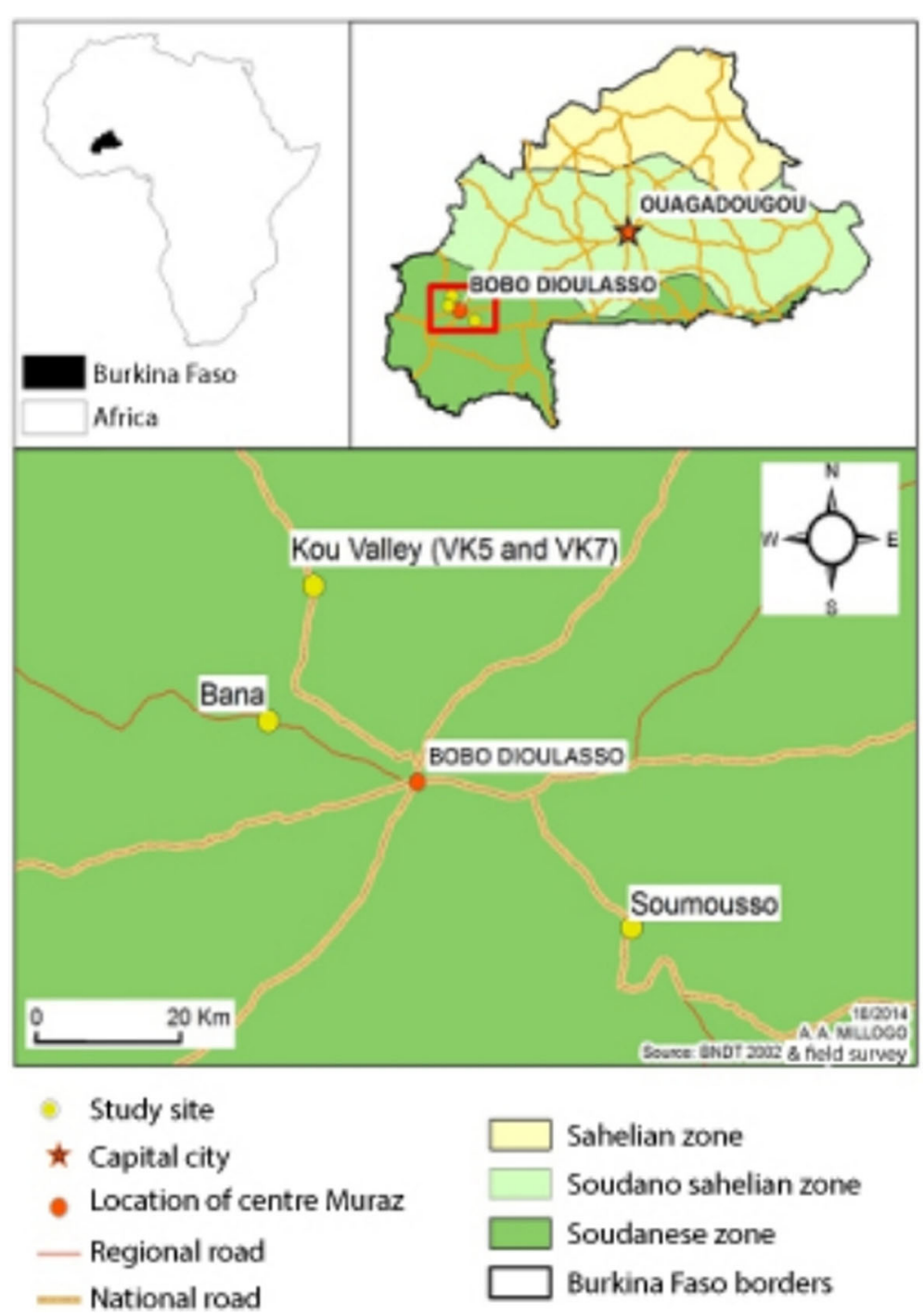

Fig. 1 Rhizosphere and mosquito collection sites 
Fungal isolates from rhizospheres or mosquitoes were identified using macro-morphological characters, such as conidiogenesis, estimation of radial growth, spore color and mycelia texture of the isolates on PDA media according to Humber [8]. In addition, we used microscopic morphology to identify Metarhizium spp. spores as described by Fernandes et al. [9]. Met_S10 and Met_S26 were confirmed as Metarhizium pingshaense through amplification and Sanger sequencing of the intron-rich region of translation elongation factor $1-\alpha[10]$.

\section{Fungal virulence on mosquitoes, honeybees and cockroaches}

Initial screens on mosquitoes revealed two promising isolates (Met_S10 and Met_S26) isolated from mosquito cadavers from Soumousso and Bana, respectively, that readily grew on PDA and were highly virulent (Additional file 1: Table S1): these strains were therefore chosen for further characterization.

\section{Bioassay on mosquitoes}

For bioassays, we used An. coluzzii adult mosquitoes reared from larval collections at the Kou Valley, Burkina Faso. Mosquitoes from this area are known to be highly resistant to multiple insecticides $[5,11]$. We carried out bioassays with local $M$. pingshaense isolates Met_S10 and Met_S26. A $M$. pingshaense strain that has been used as the foundation for development of transgenic mosquito control technologies was used as a positive control; this strain was engineered to constitutively express red fluorescent protein (RFP) [5]. Expression of RFP provides a fluorescent tag for following infection processes without altering virulence. We used an atomizer protocol for infections, as described previously
[12]. Three serial concentrations were used: $1 \times 10^{8} ; 1 \times$ $10^{7}$; and $1 \times 10^{6}$ conidia $/ \mathrm{ml}$. We confirmed that this inoculation technique was able to deliver a repeatable inoculating dose (mean \pm SE): $276 \pm 16$ spores per mosquito with $1 \times 10^{8} ; 211 \pm 13$ spores per mosquito with $1 \times 10^{7}$ spores $/ \mathrm{ml}$; and $44 \pm 3$ spores per mosquito with $1 \times 10^{6}$. Mortality was counted twice daily over two weeks.

\section{Bioassay on non-target insects}

We bioassayed Met_S10, Met_S26 and Met_RFP against a breeding line of honeybees, Apis mellifera adansonii (Latreille, 1804), as well as American cockroaches, Periplaneta americana (Linnaeus, 1758) caught in households from Soumousso. Spore doses were $1 \times 10^{8}, 1 \times$ $10^{7}$ or $1 \times 10^{6}$ conidia/ml, as described previously [5]. Following treatment, insects were kept in our insectarium at $25.3 \pm 1{ }^{\circ} \mathrm{C}$ and $70 \pm 10 \%$ relative humidity. Mortality was counted twice daily over two weeks.

\section{Results and discussion}

Metarhizium spp. were isolated from rhizosphere soil samples across 3 sample sites: the Kou Valley, Bana and Soumousso. From the Kou Valley and Bana, we isolated 362 and 306 soil samples, respectively. Metarhizium spp. comprised $28.71 \%(n=56)$ of the isolates from Bana and $30.72 \%$ ( $n=94$ ) of the total isolated fungi from the Kou Valley. We isolated 152 fungal strains from Soumousso; of these, $113(74.34 \%)$ were Metarhizium, with a mean of 1.18 isolates/gram of soil (Additional file 2: Table S2). Soumousso is a savanna and corn crop area, and the higher proportion of Metarhizium fungi is consistent with previous studies that reported a strong association between Metarhizium spp. and soils from cultivated habitats, particularly field crops [13-15].

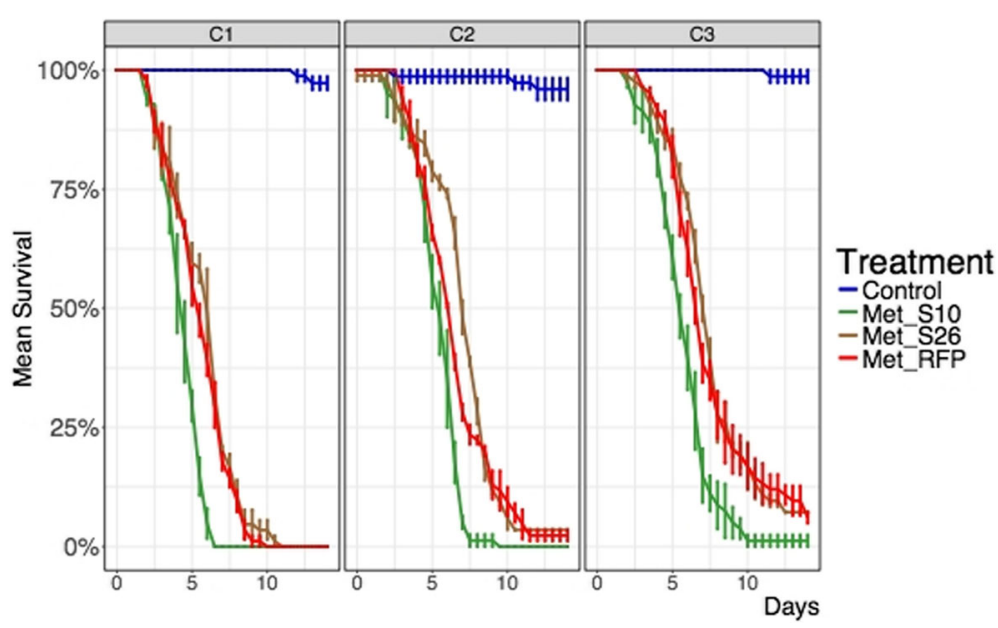

Fig. 2 Survival curves of mosquitoes infected with Burkina Faso Metarhizium pingshaense isolates at different concentrations: $\mathrm{C} 1,1 \times 10^{8}$ conidia/ $\mathrm{ml} ; \mathrm{C} 2,1 \times 10^{7}$ conidia/ml; $\mathrm{C} 3,1 \times 10^{6}$ conidia/ml 
Isolates of Metarhizium spp. represented 1\% (8/801; 3 isolates from Culex spp. and 5 isolates from Anopheles gambiae (sensu lato) of the fungi isolated from mosquitoes. Fifteen colonies of Beauveria spp. were isolated on mosquitoes (5 isolates from Aedes aegypti and 10 isolates from Anopheles gambiae (s.l.) at Soumousso). Trichoderma was the predominant genus at all sites being isolated from 56\% (Vallée du Kou) to 79\% (Soumousso) of mosquitoes (Additional file 2: Table S2). However, two Metarhizium isolates (Met_S10 and Met_S26), collected from Anopheles gambiae (s.l.), in an inhabited house in Soumousso and in a woodpile in Bana, respectively, were more virulent against mosquitoes than other isolates, including those from rhizospheres (Additional file 1: Table S1). At $1 \times 10^{8}$ and $1 \times 10^{7}$ conidia $/ \mathrm{ml}$, both strains achieved lower $\mathrm{LT}_{50}$ than Met_RFP $\left(\mathrm{LT}_{50}\right.$ of $\sim 6$ days) [16]. At the highest concentration $\left(1 \times 10^{8}\right.$ conidia/ml), the LT80 of Met_S10 (5.67 \pm 0.17 days) was significantly lower than both Met_26 (LT80 $=7.50 \pm 0.29$ days; Welch $t=-5.5, d f=3.2, P=0.01)$ and Met_RFP (7.17 \pm 0.17 days; Welch $t=-6.364, d f=4, P=0.003)$. At the lowest concentration $\left(1 \times 10^{6}\right.$ conidia $\left./ \mathrm{ml}\right)$, Met_S10 still had a significantly (Welch $t=-5.1962, d f=3.2, P=$ $0.011)$ lower LT80 (7.00 \pm 0.29 days $)$ compared to Met S26 and Met_RFP, which both had LT80's of 10 days (Fig. 2, Table 1). At intermediate concentrations, all strains achieved $80 \%$ mortality, which is the threshold value from the World Health Organization Pesticide Evaluation Scheme (WHOPES) for successful control with insecticides [17]. Thus, our results revealed higher virulence for the native isolate Met_S10, against wild-caught, insecticideresistant Anopheles coluzzii. The virulence of these isolates to mosquitoes is also higher than isolates from Benin and

Table $1 \mathrm{LT}_{80} \mathrm{~S}$ and grouping $\mathrm{LT}_{80}$ values for Anopheles coluzzii adults treated with Burkina Faso local Metarhizium pingshaense strains (Met_10 and Met_26) compared with wild type Metarhizium pingshaense expressing red fluorescent protein (Met_RFP) at three different concentrations

\begin{tabular}{|c|c|c|c|}
\hline $\begin{array}{l}\text { Concentration } \\
\text { (conidia/ml) }^{\mathrm{a}}\end{array}$ & Treatment & $\mathrm{LT}_{80}+\mathrm{SE}$ (days) & Grouping $L T_{80}^{b}$ \\
\hline \multirow[t]{3}{*}{$\mathrm{C} 1\left(1 \times 10^{8}\right)$} & Met_S10 & $5.67 \pm 0.167$ & $a$ \\
\hline & Met_S26 & $7.50 \pm 0.289$ & $b$ \\
\hline & Met_RFP & $7.18 \pm 0.167$ & $b$ \\
\hline \multirow[t]{3}{*}{$C 2\left(1 \times 10^{7}\right)$} & Met_S10 & $6.67 \pm 0.167$ & $a$ \\
\hline & Met_S26 & $8.67 \pm 0.167$ & $b$ \\
\hline & Met_RFP & $8.83 \pm 0.167$ & $b$ \\
\hline \multirow[t]{3}{*}{$C 3\left(1 \times 10^{6}\right)$} & Met_S10 & $7.00 \pm 0.289$ & $a$ \\
\hline & Met_S26 & $10.00 \pm 0.500$ & $b$ \\
\hline & Met_RFP & $10.00 \pm 1.041$ & $\mathrm{~b}$ \\
\hline
\end{tabular}

in Kenya where Metarhizium anisoplae strains were originally isolated from a white fly, Trialeurodes vaporariorum $[16,18]$.

We bioassayed honeybees and cockroaches with the local strains and Met_RFP. However, even at the highest spore dosage $\left(1 \times 10^{8}\right.$ conidia/ml $)$, these fungi did not significantly increase mortality compared to controls containing no conidia (Table 2). Fewer than 5\% of honeybees and cockroaches died during the bioassays, and no mycosis was observed on any cadavers. This is in agreement with previous studies that report Met_RFP is a specialist to Culicidae [5]. The host ranges of different Metarhizium strains are chiefly controlled by recognition events on the cuticle [19], and the cuticles of

Table 2 Two week-survival and grouping survival values for nontarget insects (Honeybees and Cockroachs) treated with Burkina Faso local Metarhizium pingshaense strains (Met_10 and Met_26) compared with wild type Metarhizium pingshaense expressing red fluorescent protein (Met_RFP) at three different concentrations and a control (0.01\% Tween)

\begin{tabular}{|c|c|c|c|c|}
\hline $\begin{array}{l}\text { Non-target } \\
\text { insect }\end{array}$ & $\begin{array}{l}\text { Concentration } \\
\text { (conidia/ml) }^{\mathrm{a}}\end{array}$ & Treatment & $\begin{array}{l}\text { Survival } \\
+ \text { SE (\%) }\end{array}$ & $\begin{array}{l}\text { Grouping } \\
\text { survival }^{b}\end{array}$ \\
\hline \multirow[t]{12}{*}{ Honeybee } & \multirow[t]{4}{*}{$\mathrm{C} 1\left(1 \times 10^{8}\right)$} & Control & $93.8 \pm 1$ & $\mathrm{a}$ \\
\hline & & Met_RFP & $98.2 \pm 1$ & a \\
\hline & & Met_S10 & $98.1 \pm 2$ & a \\
\hline & & Met_S26 & $94.6 \pm 2$ & a \\
\hline & \multirow[t]{4}{*}{$C 2\left(1 \times 10^{7}\right)$} & Control & $94.6 \pm 1$ & a \\
\hline & & Met_RFP & $97.3 \pm 2$ & a \\
\hline & & Met_S10 & $98.3 \pm 1$ & a \\
\hline & & Met_S26 & $97.3 \pm 0$ & a \\
\hline & \multirow[t]{4}{*}{$\mathrm{C} 3\left(1 \times 10^{6}\right)$} & Control & $95.3 \pm 1$ & a \\
\hline & & Met_RFP & $99.1 \pm 1$ & a \\
\hline & & Met_S10 & $99.0 \pm 0$ & a \\
\hline & & Met_S26 & $95.1 \pm 2$ & a \\
\hline \multirow[t]{12}{*}{ Cockroach } & \multirow[t]{4}{*}{$\mathrm{C} 1\left(1 \times 10^{8}\right)$} & Control & $95.7 \pm 2$ & a \\
\hline & & Met_RFP & $97.8 \pm 2$ & a \\
\hline & & Met_S10 & $98.8 \pm 1$ & a \\
\hline & & Met_S26 & $97.5 \pm 1$ & a \\
\hline & \multirow[t]{4}{*}{$C 2\left(1 \times 10^{7}\right)$} & Control & $96.1 \pm 2$ & a \\
\hline & & Met_RFP & $97.5 \pm 1$ & a \\
\hline & & Met_S10 & $98.7 \pm 1$ & a \\
\hline & & Met_S26 & $97.7 \pm 1$ & a \\
\hline & \multirow[t]{4}{*}{ C $3\left(1 \times 10^{6}\right)$} & Control & $96.0 \pm 1$ & a \\
\hline & & Met_RFP & $97.0 \pm 1$ & a \\
\hline & & Met_S10 & $97.0 \pm 1$ & a \\
\hline & & Met_S26 & $96.0 \pm 1$ & a \\
\hline
\end{tabular}

Abbreviation: $S E$ standard error of the mean

${ }^{a}$ In $0.01 \%$ Tween 80

bPairwise comparison of survival mean values per spraying conidia suspension concentrations; treatments with no letters in common differ significantly at $P<0.05$ 
honeybees, cockroaches and mosquitoes would likely have many topographical and chemical differences.

Despite being more virulent than other WT Metarhizium strains, the Burkinabe Anopheles-derived isolates are still significantly less effective than transgenic strains expressing arthropod toxins [5]. However, our results suggest that these native Burkinabe Metarhizium strains would make attractive candidates for transgenic virulence enhancement and subsequent use as transgenic biocontrol agents.

\section{Conclusion}

Native fungal isolates may offer a superior alternative to introducing a foreign biocontrol strain, as they may be better adapted to both kill local mosquitoes and survive local conditions. There are also regulatory and ecological advantages to using strains already present in the country or in the ecosystem. This study provides a promising precedent for isolating local Metarhizium strains for application in mosquito biological control, and it lays a foundation for future transgenic biocontrol projects in Burkina Faso.

\section{Additional files}

Additional file 1: Table S1. Preliminary infections data on mosquitoes. (XLSX $34 \mathrm{~kb}$ )

Additional file 2: Table S2. List of fungal strains isolated from rhizosphere and mosquitoes. (XLSX $72 \mathrm{~kb}$ )

\section{Abbreviations}

Met_S10: Metarhizium pingshaense strain No. 10; Met_S26: Metarhizium pingshaense strain No. 26; Met_RFP: Metarhizium pingshaense expressing red fluorescent protein (RFP); $L_{50}$ : Median (50\%) lethal time after exposure to fungal infections; $\mathrm{LT}_{80}$ : $80 \%$ lethal time after exposure to fungal infections; SE: Standard error

\section{Acknowledgements}

We are very grateful to Dr Amélie Vantaux for critical reading of the manuscript and to Dr Ali Drabo, Gnada Kobo Daniel, Eli Kabré, Athur D. Djibougou, Jacques E. Gnambani and Issiaka Saré for the technical assistance.

\section{Funding}

This work was supported by the US National Institute of Allergy and Infectious Diseases of the National Institutes of Health (Grant RO1 Al106998 to Raymond St. Leger) under Subaward Z047801/Centre Muraz to Dr Abdoulaye Diabate.

\section{Availability of data and materials}

The datasets generated during the current study are available from the corresponding author upon request.

\section{Authors' contributions}

$A D, B L, R K D, A S$ and $E B$ designed the experiments. $E B$ and $B L$ performed the experiments and analysed the data. EB, BL, RJSL and AD wrote the manuscript. All authors read and approved the final manuscript.

\section{Ethics approval}

Ethical permissions were obtained through the Institutional Review of Institut de Recherche en Science de la Santé (IRSS) and Centre Muraz ethics committee (A012-2014/CE-CM). Prior authorization was granted from the Burkina Faso National Biosecurity Agency for sampling native fungi from rhizosphere of plants and mosquitoes (Ministerial Ordinance No. 2012-059/
MRSI/SG/ANB). In addition, authorization was granted for importing and using both wild types and transgenic Metarhizium fungi for semi-field and lab work (Ministerial Ordinance No.2012-061/MRSI/SG/ANB). All bioassays with mosquitoes and non-target insects were carried out in strict accordance with the recommendations in the Guide for the Care and Use of Laboratory Animals of the National Institutes of Health. In addition, the protocols followed the IRSS Animal Welfare Assurance A5926-01.

Consent for publication

Not applicable.

\section{Competing interests}

The authors declare that they have no competing interests.

\section{Publisher's Note}

Springer Nature remains neutral with regard to jurisdictional claims in published maps and institutional affiliations.

\section{Author details}

${ }^{1}$ Institut de Recherche en Sciences de la Santé/Centre Muraz, Bobo-Dioulasso, Burkina Faso. ${ }^{2}$ Department of Entomology, University of Maryland, College Park, Maryland, USA. ${ }^{3}$ Laboratoire d'Entomologie Fondamentale et Appliqué/UFR-SVT/Université Ouaga 1, Pr. Joseph KI-Zerbo, Ouagadougou, Burkina Faso.

Received: 4 December 2017 Accepted: 15 March 2018 Published online: 27 March 2018

References

1. Farenhorst M, Knols BGJ. Fungal entomopathogens for the control of adult mosquitoes: a look at the issues. Proc Netherlands Entomol Soc Meet. 2007; 18:51-9.

2. Thomas MB. Biological control of human disease vectors: a perspective on challenges and opportunities. BioControl. 2018;63:61-9.

3. Wang C, St Leger RJ. A scorpion neurotoxin increases the potency of a fungal insecticide. Nat Biotechnol. 2007;25:1455-6.

4. Fang W, Lu H-L, King GF, St. Leger RJ. Construction of a hypervirulent and specific mycoinsecticide for locust control. Sci Rep. 2014;4:7345.

5. Bilgo E, Lovett B, Fang W, Bende N, King GF, Diabate A, et al. Improved efficacy of an arthropod toxin expressing fungus against insecticideresistant malaria-vector mosquitoes. Sci Rep. 2017;7:3433.

6. Liao X, Lovett B, Fang W, St Leger RJ. Metarhizium robertsii produces indole3-acetic acid, which promotes root growth in Arabidopsis and enhances virulence to insects. Microbiology. 2017;163:980-91.

7. Wyrebek M, Huber C, Sasan RK, Bidochka MJ. Three sympatrically occurring species of Metarhizium show plant rhizosphere specificity. Microbiology. 2011;157:2904-11.

8. Humber RA. Entomopathogenic fungal identification. 2005. Available at https://www.ars.usda.gov/ARSUserFiles/80620520/apswkshoprev.pdf. Accessed 17 Nov 2017

9. Fernandes ÉKK, Keyser CA, Rangel DEN, Foster RN, Roberts DW. CTC medium: a novel dodine-free selective medium for isolating entomopathogenic fungi, especially Metarhizium acridum, from soil. Biol Control. 2010;54:197-205.

10. Bischoff JF, Rehner SA, Humber RA. A multilocus phylogeny of the Metarhizium anisopliae lineage. Mycologia. 2009;101:512-30.

11. Namountougou M, Simard F, Baldet T, Diabaté A, Ouédraogo JB, Martin T, et al. Multiple insecticide resistance in Anopheles gambiae s.l. populations from Burkina Faso, West Africa. PLoS One. 2012;7(11):e48412.

12. Fang W, Vega-Rodriquez J, Ghose AK, Jacobs-Lorena M, Kang A, St Leger RJ. Development of transgenic fungi that kill human malaria parasites in mosquitoes. Science. 2011;331:1074-7.

13. Keyser CA, De Fine Licht HH, Steinwender BM, Meyling NV. Diversity within the entomopathogenic fungal species Metarhizium flavoviride associated with agricultural crops in Denmark. BMC Microbiol. 2015;15:249.

14. Sánchez-Peña SR, Lara JS-J, Medina RF. Occurrence of entomopathogenic fungi from agricultural and natural ecosystems in Saltillo, México, and their virulence towards thrips and whiteflies. J Insect Sci. 2011;11:1.

15. Quesada-Moraga E, Navas-Cortés JA, Maranhao EAA, Ortiz-Urquiza A, Santiago-Álvarez C. Factors affecting the occurrence and distribution of 
entomopathogenic fungi in natural and cultivated soils. Mycol Res. 2007; 111:947-66.

16. Scholte EJ, Takken W, Knols BGJ. Pathogenicity of five east African entomopathogenic fungi against adult Anopheles gambiae s.s. mosquitoes (Diptera: Culicidae). Proc Exp Appl Entomol Soc. 2003;14:25-9.

17. World Health Organization. Guidelines for laboratory and field-testing of long-lasting insecticidal nets. Who/Htm/Ntd/Whopes/20131; 2013. www who.int/about/licensing/copyright_form/en/index.html. Accessed 26 Nov 2017.

18. Howard AFV, Koenraadt CJM, Farenhorst M, Knols BGJ, Takken W. Pyrethroid resistance in Anopheles gambiae leads to increased susceptibility to the entomopathogenic fungi Metarhizium anisopliae and Beauveria bassiana. Malar J. 2010;9:168.

19. Wang C, St Leger RJ. Developmental and transcriptional responses to host and nonhost cuticles by the specific locust pathogen. Society. 2005;4:937-47.

Submit your next manuscript to BioMed Central and we will help you at every step:

- We accept pre-submission inquiries

- Our selector tool helps you to find the most relevant journal

- We provide round the clock customer support

- Convenient online submission

- Thorough peer review

- Inclusion in PubMed and all major indexing services

- Maximum visibility for your research

Submit your manuscript at www.biomedcentral.com/submit
Biomed Central 